\title{
LED lighting with remote monitoring and controlling system for indoor greenhouse
}

\begin{abstract}
Greenhouse generally is a house that isolates its internal environment from its external environment. The aim of this work is to create an artificial environment for plants where the goal is to accelerate plant growth. This will contribute to agriculture industries like in fruits and vegetables production. The project involves the use of ARM board as platform to collect and control variable parameter and Web-based graphical user interface for monitoring and controlling the system. It is shown that the greenhouse environment can be monitored and controlled through Internet via built in Wi-Fi on the controller board.
\end{abstract}

Keyword: Artificial environment; LED; Agriculture; Programming; Monitor; Internet 